\title{
Tingkat Ekspresi Emosi pada Caregiver Skizofrenia di Kecamatan Kersamanah, Kabupaten Garut
}

\author{
Sarah Khairunnisa Zahrani", Farida Coralia \\ Prodi Ilmu Psikologi, Fakultas Psikologi, Universitas Islam Bandung, \\ Indonesia. \\ *sarah.khairunnisa@gmail.com, coralia_04@yahoo.com
}

\begin{abstract}
Kersamanah District is the sub-district with the highest number of people that have schizophrenia in Garut with a total of 107 sufferers, and the Sukamerang Public Health Center is the only health facility located there, along these lines, Kersamanah District is called the "Insane Village". Schizophrenia is a psychotic disorder in which the sufferer needs someone who can help provide care and meet daily needs. This person is referred to as a caregiver. Caregivers who experience stress while providing care, are likely to experience high emotional expressions that can trigger an increase in the frequency of relapse in people with schizophrenia. The study was conducted to determine the level of emotional expression experienced by schizophrenic caregivers. This study was conducted in Kersamanah District, Garut while utilizing a quantitative descriptive approach. The sample of respondents upwards of 45 people who are primary family caregivers by giving a questionnaire was a measuring instrument for Family Questionnaire (FQ) adapted by Nurtantri in 2005. The results showed that schizophrenic caregivers in Kersamanah District had a high emotional
\end{abstract}

Keywords: Caregiver, Emotional Expression, Schizophrenia.

Abstrak. Kecamatan Kersamanah merupakan kecamatan dengan angka pengidap gangguan skizofrenia tertinggi di Kabupaten Garut dengan jumlah 107 penderita, dan Puskesmas Sukamerang sebagai satu-satunya fasilitas kesehatan yang berada di sana, oleh karena itu, Kecamatan Kersamanah juga dikenal sebagai "Desa Gila". Skizofrenia merupakan gangguan psikotik di mana penderitanya membutuhkan seseorang yang dapat membantu dalam memberi perawatan serta pemenuhan kebutuhan sehari-hari. Orang ini disebut sebagai caregiver. Caregiver yang mengalami tekanan saat memberikan perawatan, memungkinkan untuk mengalami ekspresi emosi yang tinggi yang dapat memicu kenaikan frekuensi kekambuhan pada penderita skizofrenia. Penelitian dilakukan untuk mengetahui tingkatan ekspresi emosi yang dialami oleh caregiver skizofrenia. Studi ini dilakukan di Kecamatan Kersamanah, Kabupaten Garut dengan menggunakan pendekatan deskriptif kuantitatif. Sampel responden sebanyak 45 orang yang merupakan caregiver keluarga primer dengan cara memberikan kuesioner yang merupakan alat ukur Family Questionnaire (FQ) yang diadaptasi oleh Nurtantri pada tahun 2005. Hasil penelitian menunjukkan bahwa caregiver skizofrenia di Kecamatan Kersamanah memiliki ekspresi emosi yang tinggi dengan persentase $73.33 \%$, dengan aspek critical comment (CC) sebesar $48.95 \%$ dan aspek emotional over involvement (EOI) sebesar $51.04 \%$.

Kata Kunci: Caregiver, Ekspresi Emosi, Skizofrenia. 


\section{A. Pendahuluan}

Kabupaten Garut dari total penduduk 3.003.304 dengan angka gangguan jiwa 4.805 orang menjadi kategori tertinggi di Jawa Barat (Hidayat, 2014). Kasus gangguan jiwa di Garut pada tahun 2015 paling menonjol terjadi di Kecamatan Kersamanah berjumlah 153 orang, dan di Kecamatan Cibatu berjumlah 56 orang yang mengalami gangguan jiwa (Puskesmas Kersamanah, 2018). Kecamatan Kersamanah sendiri biasa disebut dengan "Desa Gila" dikarenakan banyak penduduknya yang mengalami gangguan jiwa. Berdasarkan data dari Puskesmas Kecamatan Kersamanah yaitu Puskesmas Sukamerang, saat ini tercatat ada 185 orang yang mengalami gangguan jiwa, 107 orang diantaranya mengalami skizofrenia.

Skizofrenia sendiri merupakan gangguan psikotik yang ditandai dengan munculnya gangguan dengan realita, gangguan proses pikir, emosi, persepsi, dan perilaku (Ibrahim, 2011). Orang yang mengalami psikotik memerlukan dukungan dari orang lain, terutama keluarga sebagai orang yang merawat penderita psikotik atau disebut juga caregiver. Tugastugas yang dilakukan caregiver dapat memicu kenaikan tingkat ekspresi emosi yang dialami.

Prasurvei dilakukan di Kecamatan Kersamanah dengan 14 orang caregiver keluarga primer sebagai sampelnya. Hasilnya, para caregiver memiliki perilaku yang berbeda-beda dalam memberikan perawatan, ada caregiver yang melakukan tugasnya dari awal hingga akhir, hingga tidak dapat meninggalkan penderita (emotional over involvement) dan ada caregiver yang awalnya merawat namun semakin lama kehilangan motivasi merawat dan kehilangan kepedulian terhadap penderita. Hal tersebut yang menyebabkan tercatat 52 penderita yang drop out atau menghentikan perawatan di puskesmas apabila mengalami kekambuhan. Selain itu, tercatat ada tiga orang penderita skizofrenia yang mengalami pemasungan dan mendapat perilaku yang kurang baik dari keluarganya, seperti pengabaian, dan mengkritik penderita setiap waktu (critical comments). Gambaran diatas mengindikasikan adanya perbedaan ekspresi emosi yang ditampilkan oleh para caregiver kepada penderita skizofrenia. Selain itu, caregiver mengalami perasaan malu apabila penderita sudah kambuh, marah, dan lelah dalam menjalankan tugasnya. Pemahaman caregiver mengenai gangguan skizofrenia di Kecamatan Kersamanah pun masih terbilang rendah, sebagian besar dari mereka mendeskripsikan gangguan skizofrenia sebagai gangguan di mana penderitanya sering berjalan-jalan dengan jarak yang jauh dan perilaku penderita yang marah-marah serta sering berhalusinasi. Akan tetapi, mereka tidak memahami bagaimana sebenarnya gangguan dari segi medis dan penyebab gangguan skziofrenia.

Menurut Brown (1950) ekspresi emosi merupakan kesatuan perasaan, emosi, dan sikap yang ditampilkan oleh pemberi perawatan (caregiver), kepada penderita skizofrenia. Ekspresi emosi itu sendiri terdiri dari sikap seperti permusuhan, kritik yang berlebihan, dan dukungan yang tidak tepat. Ekspresi emosi memiliki hubungan yang bermakna dengan frekuensi kekambuhan penderita, bahkan di Jepang, ekspresi emosi dalam keluarga merupakan prediktor yang baik terhadap kekambuhan skizofrenia (Mino, dkk., 1997).

Penelitian mengenai ekspresi emosi pada caregiver gangguan skizofrenia sudah pernah dilakukan oleh Kavanagh pada tahun 1992, dengan hasil caregiver memiliki ekpresi emosi yang tinggi mencapai $48 \%$, namun penelitian yang dilakukan oleh Jek Pardede, dkk., pada tahun 2015 di rumah sakit Prof. Dr. Muhammad Idrem memiliki hasil yang berbeda, justru mayoritas caregiver keluarga skizofrenia memiliki ekspresi emosi yang rendah dengan persentase $72.7 \%$, di sini adanya perbedaan hasil penelitian.

Berdasarkan informasi yang sudah dijelaskan, maka peneliti tertarik untuk mengetahui tingkatan ekspresi emosi pada caregiver skizofrenia di Kecamatan Kersamanah, Kabupaten Garut.

Selanjutnya, tujuan dalam penelitian ini yaitu untuk mendapatkan data tentang besarnya ekspresi emosi caregiver keluarga primer penderita skizofrenia di Kecamatan Kersamanah, Kabupaten Garut.

\section{B. Metodologi Penelitian}

Menurut Brown (1950) ekspresi emosi merupakan kesatuan perasaan, emosi, dan sikap yang ditampilkan oleh pemberi perawatan (caregiver), kepada penderita skizofrenia. Ekspresi emosi 
itu sendiri terdiri dari sikap seperti permusuhan, kritik yang berlebihan, dan dukungan yang tidak tepat (Wick, dan Nelson, 2006).

Ekspresi emosi yang dirasakan merupakan ekspresi emosi yang dilakukan oleh caregiver kepada penderita skizofrenia. Dalam hal ini merupakan komunikasi yang terjalin diantara keduanya. Adapun aspek dari ekspresi emosi menurut George Brown (1950) dibagi menjadi tiga, yaitu:

1. Kebencian (Hostility), Merupakan keadaan di mana keluarga (dalam hal ini caregiver) menyerang penderita dikarenakan penyakitnya, bukan karena apa yang dilakukan penderita. Caregiver berpendapat bahwa penyakit penderita merupakan tanggungjawab penderita.

2. Komentar Kritik (Critical Comment), Kritik bisa berupa kata-kata negatif yang dilontarkan caregiver kepada penderita skizofrenia. Kritik ini bisa terjadi apabila caregiver merasa tidak menyukai penderita yang ditunjukkan dengan perilaku yang menampakkan kemarahan.

3. Ekspresi Emosi yang Berlebihan (Emotional Over Involvement), respon caregiver yang berlebihan terhadap kondisi penderita. Hal ini biasanya ditandai dengan terlalu over dalam menjaga penderita, caregiver merasa bersalah atas apa yang terjadi dengan penderita. Caregiver terlalu melibatkan diri karena memiliki rasa kasihan yang berlebihan.

Aspek dari ekspresi emosi menurut Brown ini mulai mengalami perkembangan. Aspek positif dinilai kurang berkontribusi sehingga pada akhirnya aspek ini memiliki dua kelompok, yaitu critical comments (CC) dengan aspek kekerasan atau hostility masuk ke dalam aspek critical comments, yang merupakan kecenderungan keluarga berperilaku kasar, mengkritik, dan tidak memberikan dukungan kepada penderita skizofrenia. Sedangkan aspek lainnya yaitu adalah emotional over involvement (EOI) merupakan ekspresi emosi yang berlebihan kepada penderita skizofrenia. Seperti sikap menyalahkan diri sendiri terhadap kondisi penderita yang sakit (Brown, 1950); (Dewi Khurriyah, 2019).

Menurut Brown, 1950 (Weisman, et al., 2003), kategori ekspresi emosi pada caregiver dapat dibagi menjadi dua, yaitu:

1. Ekspresi emosi yang tinggi (High EE).

Menujukkan sikap caregiver yang penuh dengan kebencian dan kritikan kepada penderita. Caregiver berpendapat bahwa perilaku penderita dapat berubah dengan kritikan.

2. Ekspresi emosi yang rendah (Low EE).

Ditandai dengan sikap yang lebih minim terharap kritik. Caregiver merasa bahwa penderita tidak memiliki kendali terhadap kondisinya saat ini, sehingga caregiver merasa simpati. Hal ini terjadi dikarenakan caregiver sudah memiliki pengetahuan yang baik mengenai gangguan yang dialami penderita sehingga ia lebih bisa memahami penderita.

Ada beberapa faktor yang dapat mempengaruhi ekspresi emosi individu. Hal inilah yang menyebabkan tingkatannya pada setiap orang berbeda - beda:

1. Faktor biologis, hal ini bisa meliputi cacat genetik atau kelainan gen, bagian tubuh yang diturunkan, watak, proses emosi yang berlebihan, serta patologi otak (Baihaqi et al. dalam Widyastuti, 2011).

2. Faktor psikologis, seperti emosional, status mental, atau kejiwaan individu tersebut. Hal ini bisa disebabkan oleh pola asuhan yang salah, hubungan patologis dengan keluarga, ketergantungan penderita dengan keluarga, dan jenis kelamin (Widyastuti, 2011). 


\section{Hasil Penelitian dan Pembahasan}

Tabel 1. Tingkat Ekspesi Emosi Responden

\begin{tabular}{cc}
\hline Aspek & \% \\
\hline Ekpresi Emosi Rendah & 26.67 \\
Ekspresi Emosi Tinggi & 73.33
\end{tabular}

Berdasarkan tabel 1 dapat disimpulkan bahwa caregiver skizofrenia primer di Kecamatan Kersamanah mengalami ekspresi emosi yang tinggi, dengan jumlah 33 responden atau $73.33 \%$.

Tabel 2. Kategori Aspek Ekspresi Emosi Responden

\begin{tabular}{lcc}
\hline \multicolumn{2}{c}{ Aspek } & \% \\
\hline Critical Comment (CC) & 48.95 \\
Emotional & Over Involvement & 51.04 \\
(EOI) & &
\end{tabular}

Pada tabel 2 menunjukkan bahwa aspek ekspresi emosi yang dirasakan oleh caregiver skizofrenia primer di Kecamatan Kersamanah hampir seimbang, dikarenakan setiap aspeknya muncul dengan besaran yang tidak jauh berbeda.

\section{DISKUSI}

Hasil penelitian pada hipotesis penelitian menyatakan bahwa tingginya angka ekspresi emosi yang dialami caregiver di Kecamatan Kersamanah, dengan persentase $73.33 \%$. Dengan kata lain, sikap caregiver penuh dengan kebencian dan kritikan kepada penderita. Caregiver berpendapat bahwa perilaku penderita dapat berubah dengan kritikan. Oleh karena itu, caregiver dengan ekspresi emosi yang tinggi sering membuat penderita mengalami kekambuhan karena kritik verbal agresif yang diberikan juga berpengaruh pada kepribadian penderita. Hal ini sesuai dengan definisi high EE menurut Brown (Weisman, Nuechler, Goldstein, dan Snyder; 1998 dalam McDonagh, 2003). Hal ini sesuai dengan penelitian yang dilakukan oleh Kavanagh, bahwa caregiver memiliki ekspresi emosi yang tinggi.

Tingginya ekspresi emosi dapat dipengaruhi oleh beberapa faktor, yang pertama adalah usia caregiver. Dalam penelitian ini, responden dengan usia 41-60 tahun lebih rentan mengalami ekspresi emosi dengan persentase $42.22 \%$. Hal ini disebabkan karena pada tahap perkembangan dewasa madya, manusia akan mengalami kesusahan fisik sebagai akibat dari terlalu banyak bekerja, rasa cemas yang berlebihan, ataupun kurangnya memperhatikan kehidupan yang membuat mereka lebih rentan untuk merasakan perasaan negatif yang dapat memicu ekspresi emosi mereka (Lesmana, 2014).

Selanjutnya adalah jenis kelamin, responden yang berjenis kelamin perempuan lebih banyak mengalami high EE dengan persentase 53.33\%. Hal ini disebabkan laki-laki cenderung lebih sulit untuk mengungkapan atau mengekspresikan perasaan yang ia rasakan (Widyastuti, 2011).

Berdasarkan hasil perhitungan aspek, responden menampilkan aspek critical comment sebesar $48.95 \%$, dan aspek emotional over involvement $51.04 \%$. Yang artinya, caregiver skizofrenia di Kecamatan Kersamanah memberikan ungkapan kritik pada penderita disertai dengan intonasi suara yang tinggi, suara mengalami perubahan dan kekerasan, serta cara bicara yang cepat. Selain itu caregiver terlalu over dalam menjaga penderita, dan merasa bersalah atas apa yang terjadi dengan penderita. Caregiver terlalu melibatkan diri karena memiliki rasa kasihan yang berlebihan. Walaupun terkesan positif, namun hal ini dapat memberikan dampak negatif bagi penderita. Seperti penderita menjadi tidak mandiri dan terlalu bergantung pada caregiver (George Brown, 1950).

Penelitian yang dilakukan oleh Rina Sugiyanti pada tahun 2017 memberikan hasil bahwa faktor kuat yang dapat mempengaruhi rendahnya ekspresi emosi adalah diberikannya 
treatment berupa psikoedukasi kepada para caregiver, sedangkan di Kecamatan Kersamanah, tidak pernah ada kegiatan khusus untuk para caregiver termasuk kegiatan psikoedukasi. Hal ini bisa menjadi salah satu penyebab mengapa ekspresi emosi di Kecamatan Kersamanah menjadi tinggi. Brdasarkan hasil prasurvei didapatkan data bahwa sebagian besar caregiver belum memahami apa itu gangguan skizofrenia, padahal, menurut teori low EE dari Brown, pemahaman caregiver mengenai gangguan skizofrenia menjadi salah satu menyebab rendahnya ekspresi emosi. Selain itu, strategi coping merupakan salah satu indikator tinggi rendahnya ekspresi emosi caregiver (Dewi, 2018).

\section{Kesimpulan}

Dari penelitian yang telah dilakukan untuk mengetahui tingkat ekspresi emosi pada caregiver skiozfrenia di Kecamatan Kersamanah, dapat disimpulkan sebagai berikut:

1. Caregiver skizofrenia primer di Kecamatan Kersamanah umumnya memiliki ekspresi emosi yang tinggi.

2. Tingginya ekspresi emosi disebabkan oleh beberapa faktor, yaitu usia, jenis kelamin, serta pengetahuan dan pemahaman caregiver mengenai gangguan skizofrenia.

\section{Acknowledge}

Terima kasih kepada pembimbing, Farida Coralia, S.Psi., M.Psi., Psikolog yang telah membimbing pelaksanaan penelitian. Terima kasih kepada Puskesmas Sukamerang, serta seluruh responden yang telah bersedia untuk berpartisipasi dalam penelitian ini.

\section{Daftar Pustaka}

[1]Pusdatin.kemkes.go.id (Oktober, 2019). Situasi Kesehatan Jiwa di Indonesia. Diakses pada $27 \quad$ November 2020, dari https://pusdatin.kemkes.go.id/resources/download/pusdatin/infodatin/InfoDatinKesehatan-Jiwa.pdf

[2] Nurtantri, Ika Sri. 2005. Penentuan Validitas dan Reliabilitas Family Questionnaire (FQ) dalam Menilai Ekspresi Emosi pada Keluarga yang Merawat Penderita Skizofrenia di RSCM. Jakarta: Fakultas Kedokteran Universitas Indonesia.

[3]Nafiah, Hana. 2019. Studi Deskriptif pada Caregiver Pasien Skizofrenia di Kabupaten Pekalongan. Jurnal Ilmiah Kesehatan, Vol. XII, No. 1. ISSN 1978 - 3167.

[4] Nuralita, Camelia., dkk. 2015. Relationship between Caregiver Burden and Expressed Emotion in Families of Schizophrenic Patients. ID Design Press, Skopje, Republik Makedonia. eISSN 1857 - 9655. DOI: 10.3889/oamjms.2019.394

[5]Pardede, Jek Amidos., dkk. 2016. Ekspresi Emosi Keluarga dengan Frekuensi Kekambuhan Pasien Skizofrenia. Idea Nursing Journal, Vol. VII, No. 3. ISSN: 2087 - 2879.

[6]Darwin, Prasila, dkk. 2013. Burden and Emotional Expression among Caregivers of Schizophrenic Patients in a Mental Health Hospital. J Indon Med Assoc, Vol. 63, No. 2.

[7] Khurriyah, Dewi. 2019. Ekspresi Emosi Keluarga Pasien Skizofrenia yang Menjalani Pengobatan dari Rumah Sakit. Surabaya: Universitas Islam Negeri Sunan Ampel: 2019

[8] M. A, Subandi. 2011. Family Expressed Emotion in a Javanese Cultural Context. Journal Culture, Medicine, and Psychiatry. Springer Science and Bussiness Media. DOI: 10.1007/s11013-011-9220-4

[9] Hasanat, Nida Ul. 2004. Expressed Emotion pada Keluarga Penderita Gangguan Jiwa. Buletin Psikologi, Tahun XII, No. 2. ISSN $0854-7108$. 